\title{
O SUS E A ATENÇÃO PRIMÁRIA NO BRASIL: UMA ANÁLISE SOBRE O SEU FINANCIAMENTO PELO PISO DA ATENÇÃO BÁSICA FIXO' ${ }^{1}$
}

\author{
Julyan Gleyvison Machado Gouveia Lins² \\ Tatiane Almeida de Menezes ${ }^{3}$ \\ Juliane da Silva Ciríaco ${ }^{4}$
}

Um dos grandes desafios quando se estuda o Sistema Único de Saúde (SUS) brasileiro é compreender como se dá a descentralização de recursos entre as diferentes esferas de governo. Este trabalho tem por objetivo preencher essa lacuna, descrevendo de forma detalhada como ocorrem os repasses federais para a gestão da baixa complexidade nos municípios brasileiros, ou seja, a atenção básica. Primeiro, busca-se apresentar uma rápida descrição sobre a origem do SUS e o processo de aperfeiçoamento do seu mecanismo de financiamento nas três esferas de governo, enfatizando sua característica descentralizadora. Segundo, são apresentadas as ações e os serviços de atenção primária, que são ofertadas pelos municípios do país, bem como as características de uma das principais fontes desse financiamento, que é o Piso da Atenção Básica Fixo (PAB Fixo).

Palavras-chave: saúde pública; financiamento governamental em saúde; cuidados primários em saúde; Brasil.

\section{SUS AND PRIMARY CARE IN BRAZIL: AN ANALYSIS OF ITS FINANCING BY THE FIXED PRIMARY CARE FLOOR}

One of the great challenges when studying the Brazilian Unified Health System (SUS) is to understand how the decentralization of resources between different spheres of government takes place. The purpose of this paper is to fill this gap by describing in detail how federal transfers to manage low complexity in Brazilian municipalities, that is, primary care. First, it seeks to present a brief description of the origin of the SUS and the process of perfecting its financing mechanism at the three levels of government, emphasizing its decentralization characteristic. Second is the primary care actions and services that are offered by the municipalities of the country, as well as the characteristics of one of the main sources of this funding, which is the Fixed Floor of Basic Care (Fixed PAB).

Keywords: public health; government funding for health; primary health care; Brazil.

1. DOI: http://dx.doi.org/10.38116/ppp55art7

2. Professor da Faculdade de Economia da Universidade Federal da Bahia (UFBA).E-mail: <julyanlink@hotmail.com>.

3. Professora da Universidade Federal de Pernambuco (UFPE).E-mail: <tatianedemenezes@gmail.com>.

4. Doutoranda do Programa de Pós-Graduação em Economia da Universidade Federal do Ceará (Caen/UFC). E-mail: $<$ julianeciriaco@hotmail.com>. 


\section{SUS Y ATENCIÓN PRIMARIA EN BRASIL: UN ANÁLISIS DE SU FINANCIACIÓN POR EL PISO FIJO DE ATENCIÓN PRIMARIA}

Uno de los grandes desafíos cuando se estudia el Sistema Único de Salud brasileño (SUS) es comprender cómo se da la descentralización de recursos entre las diferentes esferas de gobierno. El presente trabajo tiene por objetivo llenar esa brecha describiendo de forma detallada cómo ocurren los traspasos federales para la gestión de la baja complejidad en los municipios brasileños, o sea, la atención básica. En primer lugar, busca presentar una rápida descripción sobre el origen del SUS y el proceso de perfeccionamiento de su mecanismo de financiamiento en las tres esferas de gobierno, enfatizando su característica descentralizadora. Según se presentan las acciones y servicios de atención primaria que son ofrecidos por los municipios del país, así como las características de una de las principales fuentes de ese financiamiento, que es el Piso fijo de la Atención Básica (PAB Fijo).

Palabras clave: salud pública; financiamiento gubernamental en salud; atención primaria en salud; Brasil.

\section{SUS ET SOINS PRIMAIRES AU BRESIL: UNE ANALYSE DE SON FINANCEMENT PAR LE PLANCHER FIXE DE SOINS PRIMAIRES}

L'un des grands défis de l'étude du système de santé unifié brésilien (SUS) est de comprendre comment s'opère la décentralisation des ressources entre les différentes sphères de gouvernement. Le but de cet article est de combler cette lacune en décrivant en détail comment les transferts fédéraux pour gérer la faible complexité dans les municipalités brésiliennes, c'est-à-dire les soins primaires. Tout d'abord, il cherche à présenter une brève description de l'origine du SUS et du processus de perfectionnement de son mécanisme de financement aux trois niveaux de gouvernement, en insistant sur sa caractéristique de décentralisation. Deuxièmement, les actions et services de soins primaires offerts par les municipalités du pays, ainsi que les caractéristiques de l'une des principales sources de ce financement, à savoir le Plancher Fixe des Soins de Base (PAB Fixe).

Mots-clés: santé publique; financement public en santé; soins de santé primaires; Brésil.

JEL: I18; H51; 054.

\section{INTRODUÇÃO}

Uma característica marcante do Sistema Único de Saúde (SUS) é o caráter universal e gratuito dos serviços prestados - além do Brasil, podem-se destacar Reino Unido, Canadá, Austrália, França e Suécia como países que oferecem tal serviço à população. O Brasil destoa dos países citados em dois aspectos: i) por não pertencer ao grupo dos países desenvolvidos; e ii) por apresentar uma das maiores populaçóes do planeta (mais de 200 milhôes de habitantes, o quinto mais populoso). Nesse contexto, a compreensão e o detalhamento das fontes de financiamento público do SUS excita um debate político constante.

Muitos artigos nacionais recentes têm levantado resultados empíricos pertinentes sobre a temática do financiamento dos serviços públicos em saúde no país, notadamente em alguns pontos, como a eficiência de gastos em saúde e de 
que modo a descentralização de receitas poderia melhorar a alocação dos recursos públicos e os resultados nessa área. Nesse ponto, como se pode ver nos trabalhos de Remor et al. (2010), Dias et al. (2013), Andrett e Rosa (2015), Simão e Orellano (2015), Mazon, Mascarenhas e Dallabrida (2015) e Menezes (2017), por exemplo, há diversas estratégias metodológicas e quantitativas de análise, bem como o uso de diferentes bancos de dados, tanto em nível nacional quanto regional. De forma geral, o que esses trabalhos sugerem é que mais receitas destinadas a essa área, tampouco maiores gastos públicos, não implicam necessariamente melhoria da saúde coletiva. Além disso, sugerem que uma maior fiscalização governamental por meio, por exemplo, de açôes do Tribunal de Contas da União (TCU) - pode exercer uma influência positiva significativa sobre essa eficácia, uma vez que pode diminuir problemas de corrupção de desvio de recursos públicos para fins específicos.

Há inúmeros trabalhos nacionais, desde os anos 1990, que atentam estudar os mecanismos jurídicos e da estrutura do sistema de financiamento do SUS, os quais podem ajudar a entender o que aponta a literatura anteriormente citada, como se pode ver nos textos de Arretche (2003; 2004), Bastos, Santos e Tovo (2009), Marques e Mendes (2012) e Paim et al. (2011), por exemplo. De forma geral, o que esses trabalhos teóricos apontam é que a estrutura institucional e legal do SUS necessita da implantação de formas e mecanismo mais incisivos de governança e controle como um elemento importante para a diminuição dos desperdícios/ ineficácia do dinheiro público nessa área. Em termos de alocação eficiente de escassos recursos econômicos, isso é uma constataçâo relevante, uma vez que esse tipo de análise pode dar importantes contribuiçôes para o melhor entendimento de questóes de como pode ocorrer a má alocação de receitas públicas e a baixa eficácia dos gastos públicos em saúde em muitas localidades no país, como se pode constatar na literatura empírica.

Uma das características do SUS, definida pela Constituição Federal de 1988 (CF/1988), é seu caráter descentralizador. Em nível local, cabe aos municípios a gestão da baixa complexidade de tratamentos em saúde, até mesmo por uma questão de escala; e, embora o sistema de arrecadação seja tripartite, de fato fica por conta do governo central grande parte da coleta dos recursos responsáveis pelo financiamento do sistema. ${ }^{5}$ Dito isso, um dos grandes desafios quando se inicia o estudo do SUS é compreender como se dá a descentralização desses recursos, seja pela necessidade de mais trabalhos que se debrucem a destrinchar esse processo, seja pela dificuldade da compreensão dos trâmites legais e burocráticos que o cercam. Dado o exposto, este artigo tem por objetivo preencher uma lacuna, descrevendo de forma detalhada como ocorrem os repasses para a gestão da baixa complexidade

5. Segundo Mendes e Marques (2014), a União é responsável por pouco mais de $40 \%$ do financiamento do SUS, e, proporcionalmente, tem visto cair sua participação relativa desde 1991, visto que nas décadas de 1970 e 1980 era responsável por cerca de $75 \%$ desses gastos. 
pelos municípios brasileiros por meio do Piso da Atenção Básica Fixo (PAB Fixo), que é uma transferência de recursos feita de forma automática aos municípios e uma das mais importantes fontes de receita para a sustentação da atenção básica do Brasil: financia cerca de um terço da atenção básica e representou, só em 2016, ${ }^{6}$ $\mathrm{R}$ \$ 5,71 bilhões.

Com esse intuito, serão descritos os serviços assistenciais públicos de atenção primária que estão a cargo dos municípios, bem como seu mecanismo de financiamento federal do PAB Fixo. Salienta-se que o enfoque deste trabalho sobre questôes relativas à atenção primária se dá por dois motivos: o primeiro é que, pela forma que está estruturado o SUS, tais serviços são a porta de entrada do sistema; e o segundo é que, quando bem realizada, a atenção primária deveria ser responsável por solucionar, em média, de $80 \%$ a $85 \%$ dos problemas de saúde da população (Nedel et al., 2011), evitando, assim, deslocamentos desnecessários para a rede hospitalar (Caminal et al., 2001; Starfield e Shi, 2002), ou seja, a rede de média e alta complexidade, cujo custo de tratamento médio por paciente tende a ser bem mais elevado e gerar maiores pressóes de custo ao sistema de saúde (Baicker e Chandra, 2004).

Este artigo está estruturado da forma a seguir. A seção 2 apresenta uma rápida descrição sobre a origem do SUS e o processo de aperfeiçoamento do seu mecanismo de financiamento nas três esferas de governo, enfatizando sua característica descentralizadora. A seção 3 foca nos aspectos de como se dá a transferência dos recursos do governo federal para os municípios. A seção 4 apresenta as ações e os serviços de atenção básica ofertados pelos municípios do país, bem como o PAB Fixo. Por fim, a seção 5 faz as consideraçóes finais.

\section{A CRIAÇÃO DO SUS E O LONGO PROCESSO DE APERFEIÇOAMENTO DO SEU MECANISMO DE FINANCIAMENTO}

O sistema de saúde brasileiro é formado por uma complexa rede de prestadores e compradores de serviços que, do ponto de vista da origem dos recursos, é composto por um subsetor público e um subsetor privado. O subsetor público é composto por um segmento de acesso universal, que é o SUS, e um segmento de acesso restrito a clientelas específicas. O subsetor privado, por sua vez, é composto pelo segmento de planos e seguros privados de saúde (que é financiado por pré-pagamento) e um segmento autônomo que funciona mediante desembolso direto. Os componentes público e privado do sistema são distintos, mas estão interconectados, e as pessoas podem utilizar os serviços de todos os dois subsetores e segmentos, dependendo da facilidade de acesso ou de sua capacidade de pagamento (Paim et al., 2011).

6. Para mais detalhes, ver: <https://bit.ly/3oQbqap $>$. 
Segundo Arretche (2004), na real distribuição intergovernamental de funçóes do subsetor público, a União está encarregada da maior parte do financiamento e da formulação da política nacional de saúde, bem como da coordenação das açóes entre o governo federal e os governos estaduais e municipais. Embora a CF/1988 garanta que não há uma relação de dependência entre as esferas do governo, a prática funciona de modo que o Ministério da Saúde (MS) tem autoridade para tomar as decisóes mais importantes nessa política setorial, de modo que, em geral, as políticas implementadas pelos governos locais são fortemente dependentes das transferências federais e das regras definidas pelo MS. Em outras palavras, como frisa Arretche (2004), apesar da descentralização dos gastos com saúde, o governo federal, efetivamente, dispóe de fortes recursos institucionais para influenciar as escolhas dos governos locais na alocação dos recursos destinados a essa área. Essa é uma evidência que, no que diz respeito às políticas e ao financiamento da saúde no país, contrasta com a pactuação da Comissão Intergestores Tripartite $(\mathrm{CIT})^{7}-$ como se ainda vigorasse a lógica vigente antes da CF/1988, em que estados e municípios funcionassem como esferas subnacionais subordinadas ao governo federal.

A atual estrutura do sistema de saúde do Brasil é relativamente recente e se iniciou a partir do processo de redemocratização do país. Depois de um longo período de ditadura militar (1964-1985), o Brasil passou, nos anos de 1980, por uma volta ao regime democrático, que culminou com a promulgaçáo da CF/1988 e com muitas mudanças institucionais e político-administrativas. No que diz respeito às políticas públicas de saúde, embora a nova CF/1988 já tenha dado garantias quanto à atribuição do Estado brasileiro nesse sentido, a criação do SUS, com a nova Constituição, foi que permitiu que esse processo se consolidasse ainda mais, como se verá adiante.

O SUS foi regulamentado pela Lei Federal no 8.080, de 19 de setembro de 1990, que dispôs sobre a organização e regulação das ações de saúde, e pela Lei Federal no 8.142 , de 28 de dezembro de 1990, que versou sobre o financiamento da saúde e a participação popular. $\mathrm{O}$ texto da primeira lei fala sobre os objetivos e as atribuiçôes do sistema, dos seus princípios e das diretrizes, da organização e da gestão e, por fim, das competências e atribuições dos agentes responsáveis por executá-las. A segunda lei, por sua vez, foca sobre a participaçấo da comunidade na gestão do SUS e sobre as transferências intergovernamentais de recursos financeiros na área, além de outras providências. Vale salientar que essas leis são disciplinadas pela CF/1988 e são a base que fundamenta o SUS. No entanto, ao longo das décadas seguintes, esse sistema foi aperfeiçoando-se e criando mecanismos jurídicos e administrativos cada vez mais elaborados para a prestação dos serviços

7. Segundo o MS, a CIT constitui-se de foros permanentes de negociação, articulação e decisão entre gestores nos aspectos operacionais e na construção dos pactos nacionais, estaduais e regionais no SUS. O objetivo é fortalecer a governança, servir de instrumento gerencial e garantir transparência na gestão, buscando o acesso integral à assistência à saúde. 
de saúde, para melhorar a relação entre os entes da Federação no que diz respeito às atribuições de saúde e, principalmente, com relação ao financiamento dessas açôes a partir da Emenda Constitucional (EC) no 29/2000, processo que se verá em detalhes mais à frente.

Retomando 1988, com a nova Constituição e os fundamentos organizacionais do SUS, passou a haver garantias de que a saúde é direito de todo cidadão brasileiro e dever do Estado. Ao poder público caberia garantir políticas sociais que objetivem prevenir e reduzir doenças, bem como garantir o acesso universal e igualitário às açóes e aos serviços de saúde. Do ponto de vista da estrutura organizacional e administrativa, uma das principais características dos textos foi o estabelecimento de um processo de diferentes atribuições dos entes federados no que diz respeito à provisão desses serviços. Nesse sentido, passou a haver uma definição clara sobre quais são as atribuiçóes de cada ente governamental na provisão dos serviços em saúde. Além disso, os textos garantiram atendimento integral, com prioridade para açôes preventivas, mas sem prejuízo dos serviços assistenciais. A Carta Magna também estabeleceu que essas ações deveriam ser financiadas pelas três esferas de governo (municípios, estados e União) e as receitas para este fim, obtidas por meio de diferentes recursos advindos de contribuiçóes sociais, dos impostos da União, dos estados e dos municípios, além de outras possíveis fontes.

Por meio de um contínuo processo de mudanças e aperfeiçoamento nas leis, advindas tanto do Congresso Nacional (através de ECs, leis complementares etc.) quanto do MS (através de portarias, ${ }^{8}$ por exemplo), o debate do financiamento do SUS é um processo que esteve sempre em movimento ao longo de quase trinta anos. Tal dinâmica teve o objetivo de aperfeiçoar o sistema e tornar a provisão de serviços de saúde mais eficazes em termos de políticas públicas, tentar diminuir desigualdades no acesso e garantir o devido e adequado financiamento.

Mas só dez anos depois da criação desse subsistema houve garantias mínimas reais quanto ao seu financiamento, a despeito de já existir garantias legais desde a promulgação da Constituição. Desde 1988, a CF previa que deveriam ser destinados aos SUS pelo menos 30\% do Orçamento da Seguridade Social e as primeiras Leis de Diretrizes Orçamentárias (LDOs) reproduziram essa determinação. O problema é que, embora houvesse determinação legal, na prática isso não vingou. Posteriormente, o mesmo aconteceu com a Contribuição Provisória Sobre Movimentação Financeira (CPMF), que vigorou entre 1997 e 2007. Ela foi

8. A edição das portarias ministeriais tem sido um importante instrumento de coordenação das ações nacionais em saúde. As portarias consistem, na maior parte das vezes, em condicionar as transferências federais à adesão dos estados e municípios aos objetivos da política federal, aumentando, assim, a capacidade do MS de descentralizar a execução dessas ações e executar com mais facilidade as transações fundo a fundo (Arretche, 2004). Vale ressaltar que as portarias têm o papel principal de estabelecer atributos conveniais para a transferência fundo a fundo; elas não garantem o adequado financiamento, entre outros motivos, porque isso não depende da vontade administrativa do MS. 
criada como fonte adicional de receita, mas acabou como substituta de outras fontes tributárias da saúde. $\mathrm{O}$ que demonstra que não necessariamente uma vinculação legal implica sua efetivação.

Nesse processo, a EC no 29, de 13 de setembro de 2000, foi um marco histórico que determinou, de fato, a vinculação de receitas e assegurou os recursos mínimos para o financiamento das açóes e dos serviços públicos de saúde das três esferas administrativas do país. Nessa EC, houve vinculação de receitas para os estados, o Distrito Federal e os municípios; mas para a União a regra foi outra. Ficou estabelecido, por exemplo, que os municípios deveriam cumprir o mínimo de $15 \%$ de sua arrecadação de receitas próprias - que inclui repasses como o Fundo de Participação dos Municípios (FPM) -, enquanto aos estados caberia aplicar o mínimo de $12 \%$ de sua arrecadação própria. Quanto aos valores aplicados pela Uniấo, o ano de 2000 teria como base de cálculo o montante empenhado em açóes e serviços públicos de saúde (ASPS) no exercício financeiro de 1999, acrescido de, no mínimo, 5\%. Nos anos posteriores (2001-2015), a aplicação foi a do ano anterior corrigido pela variaçáo nominal do produto interno bruto (PIB). Essa EC permitiu também que houvesse a possibilidade de os percentuais mínimos serem reavaliados, pelo menos a cada cinco anos, por meio de lei complementar (LC).

Doze anos depois, a LC no 141 , de 13 de janeiro de 2012, regulamentou parte do art. 198 da CF/1988, e esperava-se que ela definisse a forma de participação da União no financiamento do SUS. Havia todo um movimento reivindicando, desde a $E C$ no $29 / 2000$, que a participação da Uniāo no financiamento do SUS fosse equivalente a $10 \%$ da receita corrente bruta, mas a retomada dessa ideia não vingou. Essa LC manteve a regra da EC no 29/2000 da fixação dos pisos, mas a grande conquista dela foi definir o que são e o que não são considerados ASPS para o cômputo dos pisos. Este foi um fato importante, pois, embora já existisse um entendimento previsto pela Resoluçáo no 322/2003, do Conselho Nacional de Saúde (CNS), sua aplicação implicou importantes mudanças nos procedimentos adotados pelos entes federados no que diz respeito em que os pisos deveriam ser efetivamente gastos. ${ }^{9}$

Mais recentemente, a EC no 86, de 17 de março de 2015, definiu as porcentagens mínimas de aplicação de recursos federais em ASPS a partir da receita corrente líquida da União. Para o ano de 2016, ficou estabelecida a aplicação de 13,2\%; 13,7\%, em 2017; 14,1\%, em 2018; 14,5\%, em 2019; e 15\%, a partir de 2020. Posteriormente, em 2016, a EC no 95 (chamada de Proposta de Emenda Constitucional - PEC do teto dos gastos) redefiniu que a aplicação mínima da União em ASPS seria de 15\% da receita corrente líquida, em 2016 e 2017. A EC no 95 apenas revogou o dispositivo da $\mathrm{EC}$ no 86 , que estabeleceu o escalonamento

9. Para mais detalhes, ver: <https://bit.ly/35WguBi>. 
de cinco anos dos percentuais para se chegar ao piso de 15\% (que iniciava em $13,2 \%)$. Além disso, definiu também que, a partir de 2018, o investimento federal mínimo seria o piso de 2017 atualizado monetariamente pelo Índice Nacional de Preços ao Consumidor Amplo, do Instituto Brasileiro de Geografia e Estatística (IPCA/IBGE) ano a ano até 2036.

\section{FINANCIAMENTO FEDERAL DOS SERVIÇOS PÚBLICOS EM SAÚDE}

No Brasil, embora haja uma forte descentralização da execução dos serviços de saúde nos municípios, o financiamento público dessas ações, como já foi exposto, é tripartite, ou seja, realizado pelos governos federal, estadual e municipal. O financiamento é obtido por meio de diversas fontes de receita, que variam substancialmente segundo a esfera do governo, como pode ser visto no anexo A.

Historicamente, o governo federal brasileiro sempre foi protagonista no financiamento do gasto público em saúde, embora a partir dos anos 1990, com a implementação da nova Constituição e do SUS, essa participação tenha tido uma tendência consistente de queda (Mendes e Marques, 2014). Para se ter uma ideia, usando estatísticas do Ipea, Mendes (2005) encontrou que, entre os anos das décadas de 1970 e 1980, pouco mais de $75 \%$ do dinheiro que sustentava esses gastos vinham da União. Em 2011, por sua vez, Mendes e Marques (2014), citando dados publicados pelo MS, mostraram que esses recursos corresponderam a pouco mais de $45 \%$ dos gastos.

Pela CF/1988, teoricamente caberia aos estados e municípios complementar o financiamento do governo federal. Porém, na prática, isso esbarra em questóes econômicas e na capacidade de arrecadação de receitas próprias desses outros entes da administração pública. Existem vários fatores importantes que podem justificar essa predominância, mas o principal consiste em ser o governo central responsável pela arrecadação da maior parte da receita tributária do país, tornando-se, por conseguinte, líder natural no que diz respeito à capacidade de financiamento dos gastos públicos em saúde. ${ }^{10}$ Contribui para essa situação o fato de $90 \%$ dos municípios brasileiros possuírem menos de 50 mil habitantes. A maioria dos casos apresenta pouco dinamismo econômico e baixa ou nula capacidade de arrecadaçáo. Dessa forma, a maior parte dos municípios depende de transferências intergovernamentais (por exemplo, o Fundo de Participação do Municípios - FPM) para a sustentaçáo da oferta dos serviços públicos locais; e a distribuição da receita disponível depois dessas transferências intergovernamentais muda completamente, aumentando a

10. No atual sistema tributário brasileiro, a arrecadação é bastante concentrada nos cinco principais impostos, dos quais quatro são federais, o que faz com que o governo federal arrecade a maior parte das receitas do país (Arretche, 2004). Como destaca a autora, isso é algo estrutural e decorrente da extrema desigualdade da arrecadação de tributos no plano horizontal, isto é, entre os governos subnacionais brasileiros. Em 2016, por exemplo, a União foi responsável por $68,27 \%$ da arrecadação total, enquanto os estados e municípios ficaram com $25,40 \%$ e 6,34\%, respectivamente. Para mais detalhes, ver: <https://bit.ly/3kWnKn3>. 
disponibilidade para o financiamento dos serviços em saúde nessas localidades. Além disso, a assimetria na capacidade de arrecadação faz com que muitos municípios, principalmente os das regióes Norte e Nordeste do país, tendam a fazer esforços significativos no aporte financeiro dos serviços públicos em saúde quando comparados aos municípios mais ricos e à União.

As transferências de recursos federais com destinação possível a açóes de saúde podem ter duas naturezas quanto à forma que são repassados aos municípios. A primeira é uma simples repartição de receitas da Uniâo via FPM, o qual consiste em uma transferência financeira para os municípios, que tem o poder de definir como aplicar esses recursos, nos limites da legislação. A segunda consiste em uma descentralização da execução de programas de âmbito nacional, que é o caso, por exemplo, das transferências do PAB Fixo e do PAB Variável. Nesse sentido, pode-se dizer que a diferença dos dois tipos de recursos é basicamente na capacidade do município ter poder de decisão sobre como gastar o dinheiro. ${ }^{11}$ Vale salientar que a política de saúde é nacional, sendo que há pactuação tripartite para os casos, não existindo imposiçáo entre esferas de governo.

Ainda no segundo caso, o repasse consiste de uma transferência que se caracteriza por meio da simples descentralização de recursos diretamente de fundos da esfera federal para a municipal, e é muito utilizada para diversas implementaçóes de açóes na área de saúde por meio do Fundo Nacional de Saúde (FNS), que consiste em um fundo federal que administra os recursos orçamentários e financeiros destinados a saúde no país. Em geral, as transferências desse tipo são realizadas por ordem bancária, para as contas específicas dos municípios, criadas especialmente para gerir esse dinheiro.

Tais contas de financiamento foram um marco no que diz respeito à possibilidade de melhor controle dos recursos federais destinados aos municípios. Contas bancárias específicas para depósitos desse tipo já existiam desde o início dos anos de 1990, quando foi estabelecido o Pacto Pela Saúde (2006), que simplificou tais contas em apenas cinco, criando os antigos blocos de financiamento da atençáo básica (que vigoraram até 2017). Tal pacto teve como objetivo estabelecer responsabilidades e compromissos entre os gestores do SUS nas três esferas do governo. Nesse pacto, o MS se preocupou em criar mecanismos para melhor organizar e fiscalizar as transferências de recursos federais para os entes da Federação. Assim, com a Portaria de no 204, de 29 de janeiro de 2007, foram criados cinco blocos de financiamento no SUS como sendo: bloco da atenção básica; bloco da média e alta complexidade; bloco da vigilância em saúde; bloco de assistência farmacêutica; bloco de gestão; e, por fim, bloco de investimento na rede de serviços de saúde. Por meio desses blocos passaram a serem feitos os repasses do MS (através do FNS)

11. Como será mostrado adiante, essa última forma de transferência sofreu uma flexibilização em dezembro de 2017. 
para todos os municípios brasileiros por meio de contas bancárias específicas para diferentes açôes de saúde. Tais blocos de financiamento vigoraram até dezembro de 2017, quando a Portaria de no 3.992, de 28 de dezembro, extinguiu tais contas e as substituiu por apenas duas: o bloco de custeio das açóes e serviços públicos de saúde e o bloco de investimento na rede de serviços públicos de saúde. O primeiro bloco, como o nome já diz, é destinado para o custeio dos serviços prestados, enquanto o segundo é destinado para o financiamento de investimento, como aquisição de equipamentos, construção de prédios etc. Essa mudança teve o intuito de permitir uma maior flexibilização no uso do dinheiro de acordos com as necessidades locais da população, e vale salientar que também não houve nenhuma alteração no método de cálculo e de distribuição dos recursos federais.

Segundo a nova portaria, os municípios passariam a ter uma maior flexibilizaçáo no uso das transferências, mas de acordo com as especificidades de cada conta. Nesse caso, por exemplo, os recursos da conta de custeio jamais poderão ser gastos em açóes previstas pelo financiamento da conta de investimento. Vale salientar que essa flexibilização é apenas financeira ou de fluxo de caixa, porque ainda foi mantida a obrigação dos estados e municípios em comprovarem o empenho, a liquidação e o pagamento de acordo com as subfunçóes que o FNS empenhou, liquidou e pagou para essa despesa de transferência. Além disso, é preciso demonstrar o cumprimento das metas pactuadas nas CITs, as quais serviram de base para a definição dos valores transferidos.

No que diz respeito ao antigo bloco de financiamento da atenção básica, este era dividido em duas subcontas: o PAB Fixo e o PAB Variável. Na primeira, os municípios recebiam financiamento para ações da atenção básica, cujos recursos eram transferidos mensalmente e de forma regular. Já na segunda, os recursos só eram repassados se o município aderisse a diferentes programas nacionais da atenção básica, que são os programas: Saúde da Família; Agentes Comunitários de Saúde; Saúde Bucal; Compensação de Especificidades Regionais; Fator de Incentivo de Atenção Básica aos Povos Indígenas; Incentivo para Atenção à Saúde no Sistema Penitenciário; Incentivo para a Intenção Integral à Saúde do Adolescente em Conflito com a Lei, em regime de internação e internação provisória; ou qualquer outro que possa ser criado por meio de ato normativo específico.

Segundo dados do MS, em 2016, o repasse federal do FNS aos fundos municipais e estaduais foi da ordem de pouco mais de $\mathrm{R} \$$ 64,67 bilhóes. Só o repasse aos municípios foi $\mathrm{R} \$ 49,50$ bilhóes, dos quais 55,64\% foram para a média e alta complexidade; 33,53\% para a atenção básica; 2,00\% para a assistência farmacêutica; 4,67\% para investimento; e 4,16\% para a vigilância em saúde. A atenção básica dos municípios abocanhou, em 2016, cerca de $\mathrm{R}$ \$ 16,6 bilhōes, dos quais $\mathrm{R}$ \$ 5,714 bilhóes corresponderam ao PAB Fixo e R \$ 11,019 bilhôes ao PAB Variável. Com uma população estimada de 207,7 milhóes de habitantes, essas transferências representaram, nesse 
ano e nível de atenção, um investimento federal per capita corrente de $\mathrm{R} \$ 79,92$. Vale destacar que, em 2016, o montante das transferências do PAB Variável ultrapassou o montante do PAB Fixo, o que é natural. Como o objetivo do PAB Fixo é dar uma garantia mínima de financiamento da atenção básica, se o município deseja mais recursos federais (desse tipo de transferência) será necessária a adesão aos programas nacionais da atenção básica, citados anteriormente, bem como o cumprimento das obrigaçôes e contrapartidas referentes a cada modalidade.

É pertinente também destacar que, ao longo dos anos, a participação do antigo bloco de financiamento da atenção básica dos recursos federais destinados aos estados e municípios vinha apresentando uma tendência de queda, contrastando com os financiamentos proporcionalmente cada vez maiores da antiga conta da média e alta complexidade de tratamento. Segundo dados do FNS, em 2000, por exemplo, a atenção básica recebia cerca de $34,84 \%$ do total do repasse, enquanto, em 2016, esse percentual era de $25,87 \%$. Na média e alta complexidade, em contraste, tínhamos em 2000 uma representatividade de 55,31\%, contra 62,69\% em 2016. Isso apresenta uma alocação cada vez maior dos recursos em assistências como a hospitalar, cujo custo de tratamento médio por paciente tende a ser bem maior que a preventiva e ambulatorial, que são as típicas da atenção básica.

\section{A ATENÇÃO BÁSICA E O PAB FIXO}

Segundo Paim et al. (2011), o desenvolvimento da atenção primária (conhecida no Brasil como atenção básica) tem recebido muito destaque no SUS. Impulsionada pelo processo de descentralização da execução de programas federais, a atenção básica tem o objetivo de oferecer acesso universal e serviços abrangentes, coordenar e expandir a cobertura para níveis mais complexos de cuidado, bem como implementar açôes intersetoriais de promoção de saúde e prevenção de doenças, sempre focando a ação em nível local e comunitário. Como destacam os autores, para isso, têm sido utilizadas diversas estratégias de repasse de recursos (por exemplo, o PAB Fixo) e estratégias organizacionais, em particular o Programa Saúde da Família (PSF).

A ênfase desse programa é a organização para que as unidades básicas de saúde (UBS) se concentrem nas famílias e comunidades e integrem a assistência médica com a promoção de saúde e as açóes preventivas (Paim et al., 2011). A UBS é uma estrutura física e organizacional que é (ou deveria ser) o primeiro contato dos usuários com o SUS. Ela é interconectada a toda a rede de atenção à saúde do sistema e, em geral, é posicionada próximo de onde as pessoas vivem de modo a facilitar o máximo possível o acesso da população ao sistema público de saúde. Os serviços podem ser desde consultas médicas de clínica geral, odontologia etc. até serviços ambulatoriais e de enfermagem. Pode haver também o encaminhamento para especialidades, o serviço hospitalar, além da realização de alguns exames e a provisão gratuita de certos medicamentos. 
O PAB Fixo, que hoje representa cerca de um terço das transferências federais para a atenção primária, foi criado em 1997 (Portaria Ministerial no 1.882) e, atualmente, a cobertura desse financiamento alcança $100 \%$ dos municípios do país. Segundo o MS, o PAB Fixo foi um mecanismo criado com o intuito de superar a lógica do pagamento por produção do modelo hospitalocêntrico, estrutura que foi muito criticada por dar ênfase ao financiamento da doença em detrimento da atenção integral à saúde e privilegiar as localidades que já possuíam estruturas de serviços (Brasil, 2001). Segundo Machado, Fortes e Somarriba (2004), o que torna a lei do $\mathrm{PAB}$ um marco na redução da desigualdade do acesso à saúde é que ela significou uma ruptura (pelo menos na atenção primária) com a estrutura dominante anterior de alocação dos recursos financeiros em função apenas de pagamentos por procedimentos.

De acordo com Barbosa et al. (2016), anteriormente, quanto maior fosse o número de estabelecimentos ambulatoriais e postos de saúde, maior seria a possibilidade de o gestor municipal receber mais recursos do SUS devido ao faturamento de consultas e procedimentos realizados. Assim, o objetivo dessa reestruturação de financiamento foi tornar o sistema da atenção básica mais equitativo, baseado na prevenção das doenças e na promoção da saúde (Melamed e Costa, 2003). Além disso, o valor repassado pelo governo federal aos municípios teve o intuito de servir como um reforço, ao ser somado às transferências estaduais e aos próprios recursos municipais destinados ao custeio de procedimentos e ações de atenção básica. Assim, essa mudança do modelo de financiamento da atenção básica não promoveu somente a ruptura com o modelo hospitalocêntrico, favorecendo a prevenção e a promoção da saúde, mas também uma distribuição mais equânime dos recursos, uma vez que rompia com o modelo anterior (que favorecia os municípios mais estruturados) ao optar pelo financiamento per capita, não mais por produção.

De acordo com Brasil (2001), o município só pode ser habilitado a receber o PAB Fixo quando estiver em condiçôes de gerir com independência os serviços de saúde do SUS. Para isso, a prefeitura deixa de ser uma simples prestadora de serviços e o secretário de saúde passa a ser o gestor do SUS no seu município. Ainda conforme Brasil (2001), para habilitar-se, a prefeitura deve atender aos critérios estabelecidos pelo MS, descritos a seguir.

1) Ter um Fundo Municipal de Saúde onde o dinheiro possa ser depositado.

2) Ter o funcionamento de um Conselho Municipal de Saúde.

3) Ter disponibilidade de equipamentos e de pessoal capazes de operar os sistemas de dados do SUS, cujas informaçóes devem ser repassadas regularmente.

4) Apresentar um Plano Municipal de Saúde. 
Essencialmente, no Plano Municipal de Saúde, deverão ser levantados dados de saúde da população e do meio ambiente urbano e rural, bem como avaliada a capacidade de atendimento dos serviços de saúde existentes no município. Além disso, devem ser definidos o objetivo e a estratégia das açôes que serão implementadas. Uma vez habilitado, o município terá direito a receber os recursos referentes à parte fixa do PAB. Para ter acesso à parte variável, por sua vez, é preciso que o município faça a adesão aos programas específicos destinados à atenção básica do governo federal, o que significa que este tipo de financiamento depende de açóes específicas implementadas na localidade (Brasil, 2001).

Desde a criação do PAB nos anos 1990, houve uma preocupação legal no que diz respeito ao direcionamento desse recurso, de modo que o dinheiro deveria ir para gastos de custeio e de capital referentes apenas aos meios fins da saúde da atençáo primária do município (anexos $\mathrm{B}$ e $\mathrm{C}$ ), ou seja, nesse caso, tinha-se uma verba dita popularmente como carimbada. Além disso, a transferência do recurso poderia ser suspensa a qualquer momento se o município não fizesse a prestação regular de contas ou a alimentação de informação sobre atendimentos ambulatoriais e internaçóes no sistema de dados do SUS, como se pode ver no anexo D. No entanto, com as recentes mudanças na regra de financiamento (com a Portaria no 3.992, de dezembro 2017), essa rigidez foi amenizada em alguns pontos, como, por exemplo, a possibilidade de aplicação dos recursos do PAB Fixo em açôes de saúde que não são específicas da atenção primária, mas de acordo com as necessidades de alocação de recursos prevista pelo prefeito, pelo secretário de saúde e pelo Plano de Saúde Municipal, desde que cumpra o pactuado na CIT e respeite as subfunçóes orçamentárias adotadas pelo FNS para essas despesas de transferência. Por seu turno, a nova portaria ainda determina que os recursos não poderão ser gastos com o pagamento de servidores inativos e servidores ativos e comissionados. Nos dois últimos casos, isso poderá ocorrer desde que esses sejam contratados para desempenhar exclusivamente funçóes relacionadas aos serviços previstos no Plano de Saúde Municipal.

Essa mudança na forma de financiamento do MS possivelmente é uma tentativa de modernização da gestão e minimização de problemas oriundos do engessamento das receitas governamentais para determinados objetivos, e por engessamento de receitas entenda-se a rigidez ou vinculação de receitas a fins precisos. Como em qualquer mudança, naturalmente há argumentos prós e contras. Se, por um lado, o engessamento de receitas pode dar uma maior garantia de que o dinheiro não será desviado, mas sim gasto em determinada e específica ação de saúde pública, por outro lado, tal rigidez não necessariamente garantirá que os serviços prestados na ponta da cadeia do SUS sejam bons, uma vez que os recursos podem ser mal alocados e haver ineficiência no uso do dinheiro. Além disso, esse tipo de rigidez tende a não levar em conta a dinâmica das necessidades sociais, 
como uma mudança na estrutura demográfica que pode apresentar-se ao longo dos anos. Nesse caso, por exemplo, o rápido envelhecimento da população exigiria a necessidade do maior financiamento de programas voltados a doenças nessa fase, em comparação a uma menor necessidade de financiamento de programas voltados à saúde materno-infantil, por exemplo. Por seu turno, uma maior flexibilidade no uso do dinheiro não necessariamente garantirá que os prefeitos e secretários de saúde vão estar mais atentos em suprir as reais necessidades da população local, além de dar maior margem à possibilidade de corrupçáo e desvios de finalidade.

É difícil prever o que poderá acontecer nos próximos anos como resultado dessa flexibilização. Uma forma de tentar antever esse processo é observar, na literatura, os trabalhos empíricos que se propóem em verificar os efeitos de maiores financiamentos de receitas intergovernamentais nos municípios do país sobre alguns indicadores-chave, como corrupção e saúde. Um exemplo clássico é o artigo de Brollo et al. (2013), que verifica os efeitos dos maiores repasses do FPM em indicadores de corrupção nos pequenos municípios do Brasil na década dos anos 2000. O uso do FPM foi proposital, primeiro por questóes metodológicas de identificação causal, segundo porque essa receita é na maior parte dela uma receita "livre", ou seja, uma vez cumprido o piso de destinação dos $25 \%$ das receitas própria do município para educação e $15 \%$ para a saúde (e isso inclui o FPM, em ambos), o prefeito tem o livre uso do dinheiro para aplicar na provisão de diferentes serviços públicos, pagamentos de funcionários, investimentos etc., ou seja, possui uma grande flexibilização no uso dos recursos públicos (evidentemente dentro dos limites legais).

O que o trabalho de Brollo et al. (2013) evidencia, por meio de uma metodologia econométrica de identificação causal, é que maiores transferências implicaram maiores índices de corrupção e também influenciaram o processo político/eleitoral das localidades. $\mathrm{O}$ artigo mostra resultados muito interessantes: i) na margem, receitas adicionais induziram a mais corrupçâo pelo fato de que, com mais receitas, os prefeitos/gestores podem desviar mais sem chamar tanta atenção, ou seja, sem um prejuízo mais perceptivel dos serviços públicos por parte da população; ii) receitas adicionais induziram a atraçâo de políticos com piores qualidades educacionais; e iii) a combinação de $i$ e $i$ fez com que aumentasse as chances do prefeito ser reeleito. O contrário só ocorre nos municípios escolhidos aleatoriamente para participar de auditoria de suas contas pelo TCU, que, por efeito de tornar públicas as irregularidades, quando existiram, acabou por selecionar melhor os prefeitos no processo eleitoral nos anos seguintes, via punição eleitoral por parte da população.

Outro trabalho que evidencia o efeito dos repasses intergovernamentais, dessa vez em um indicador de saúde, é o de Menezes (2017), que utilizou a mesma estratégia de identificação causal de Brollo et al. (2013) para verificar o efeito 
da maior descentralização de receitas intergovernamentais sobre o índice Firjan de saúde. O que o estudo sugere é que uma maior descentralização gerou uma melhora do indicador. $\mathrm{O}$ trabalho salienta também que os municípios auditados pelo TCU chegaram aos mesmos índices de saúde que os municípios não auditados com menos receitas, ou seja, eles apresentaram uma maior eficiência no uso do dinheiro. Assim, inevitavelmente, o efeito das mudanças propostas pelo MS na Portaria no 3.992/2017 precisará ser avaliado quantitativamente nos próximos anos, para termos a real dimensão dos efeitos práticos dessas mudanças nos indicadores de saúde do país, o que é uma boa oportunidade para que estudos futuros se debrucem mais empiricamente nessa temática.

Segundo a Confederação Nacional dos Municípios (CNM, 2014), em geral, na regra que teve vigência até 28 de dezembro de 2017, a transferência de recursos do PAB Fixo para o financiamento de açóes não previstas no Plano de Saúde Municipal era vedada, exceto em situaçôes emergenciais ou de calamidade pública na área de saúde, desde que devidamente justificadas. Além disso, esses recursos jamais poderiam substituir as fontes financeiras próprias do orçamento do município. No caso de açóes e serviços novos, não previstos no Plano de Saúde Municipal, estes deveriam ser submetidos à aprovação do respectivo Conselho de Saúde, que também deveria aprovar as inclusóes e alteraçóes do plano, contemplando, no mesmo exercício, as novas demandas. Outra restrição legal era a proibição de se destinar subvençóes e auxílios a instituiçóes prestadoras de serviços de saúde com finalidade lucrativa. Todas essas restriçôes faziam com que pudessem ser custeadas com o PAB Fixo (até dezembro de 2017) apenas os procedimentos pertinentes à atenção básica da saúde, como podem ser vistos detalhes nos anexos B e C.

Como destacam Mendes e Marques (2014), quando o PAB Fixo foi instituído, determinou-se um valor fixado em $\mathrm{R} \$ 10,00$ habitante/ano e, posteriormente, em 2006 , o valor chegou a $\mathrm{R} \$ 18,00$ por habitante/ano (ambos em valores correntes). Vale salientar que, de acordo com o trabalho de Mendes e Marques (2014), o valor inicial instituído $(\mathrm{R} \$ 10,00)$ já estava defasado, uma vez que estudos à época indicavam que tal quantia deveria corresponder à $\mathrm{R} \$ 12,00$ per capita. Em 2011, houve algumas importantes mudanças no que diz respeito às regras desse financiamento, de modo que, pela Portaria MS no 1.602 , o repasse monetário passou a variar de acordo com o porte populacional do município e alguns indicadores socioeconômicos, ficando entre $\mathrm{R} \$ 18,00$ e $\mathrm{R} \$ 23,00$ habitante/ano, em termos nominais. Atualmente, o valor do repasse do PAB Fixo é regido pela Portaria $\mathrm{n}^{\circ} 1.409$, de 10 de julho de 2013 (Brasil, 2013), que classificou os municípios brasileiros em quatro grupos de financiamento (anexo E). Essa classificação estabeleceu a seguinte distribuição: grupo 1, com 70,25\% dos municípios; grupo 2, com 19,84\%; grupo 3 , com 6,98\%; e grupo 4, com 2,93\% dos municípios; cuja distribuição geográfica no país pode ser visualizada na figura F.1 do anexo F. 
Como já destacado, a partir de 2011, a regra do repasse do PAB Fixo passou a ser baseada no porte populacional e em alguns indicadores socioeconômicos. Pode ser visto no anexo E que existem dois critérios de repasse, os quais fazem o município se enquadrar ou não em determinado grupo de financiamento: um corresponde ao score do indicador desenvolvido pelo MS (através de uma série de procedimentos estatísticos e de normalização) e o outro dependerá de cortes populacionais. Se analisarmos a regra de repasse apenas pelo critério populacional, teremos: no grupo 1, municípios com até 50 mil habitantes e que devem receber $\mathrm{R} \$ 28,00$; no grupo 2, municípios com mais de 50 mil habitantes e até $100 \mathrm{mil}$ habitantes, que devem receber $\mathrm{R} \$ 26,00$; no grupo 3, municípios com mais de 100 mil habitantes e até 500 mil habitantes, que devem receber $\mathrm{R} \$ 24,00$; e por fim, no grupo 4, municípios com mais de 500 mil habitantes que devem receber $\mathrm{R}$ \$23,00 de transferências teóricas.

O repasse per capita maior para municípios menos populosos é proposital. A ideia é justamente tornar mais equânime a capacidade de financiamento da atenção básica de municípios ricos e pobres. ${ }^{12}$ Atualmente, aproximadamente $90 \%$ dos municípios do país possuem menos de 50 mil habitantes. E, como destacam Brollo et al. (2013), boa parte deles apresentam baixa capacidade de arrecadação de receitas tributárias própria, dependendo muito de transferências intergovernamentais para financiar seus serviços públicos. Pode ser visto nos gráficos G.1, G.2 e G.3 do anexo G o comportamento da média de financiamento nos diferentes grupos estabelecido pela regra populacional do PAB Fixo. Os citados gráficos mostram que os municípios que recebem mais financiamento (per capita) têm menor tamanho populacional absoluto, isso acontece justamente pelo fato do PAB Fixo procurar tornar mais equânime os recursos municipais destinados a tais fins, entre diferentes localidades. ${ }^{13}$

Por fim, vale salientar que, embora o MS tenha garantido uma transferência teórica per capita, na prática o que existem são transferências reais (no sentido de efetivas), as quais podem destoar (e muito) da que é estabelecida na portaria que atualmente regula os pisos do PAB Fixo (Portaria no $1.409 / 2013$ ). O primeiro motivo é a perda do poder de compra da moeda ao longo do tempo. Inevitavelmente, o processo inflacionário entre um e outro reajuste do repasse teórico diminui a capacidade do poder de compra desse dinheiro ao longo dos anos. A

12. No Brasil, as transferências fiscais tendem a ter um limitado efeito equalizador sobre as diferenças interestaduais e intermunicipais de capacidade de gasto, sendo assim necessária a ação do governo federal para viabilizar patamares básicos de produção de serviços sociais. Em suma, a gestão federal dos programas sociais se justifica tanto por razões relacionadas à coordenação das decisões dos governos locais quanto para corrigir desigualdades de capacidade de gasto entre estados e municípios (Arretche, 2004).

13. Como é mostrado no anexo E, o tamanho populacional e alguns indicadores locais são os determinantes na definição do piso e no enquadramento no grupo de financiamento do PAB Fixo. De forma geral, quanto maior a população e pior os indicadores, maiores os repasses per capita. 0 contrário se mantém. 
última atualização do valor nominal do piso, por exemplo, ocorreu em 2013. Isso faz com que os anos de 2014 em diante, por exemplo, tenham, em termos reais, transferências per capita menores que a definida em portaria. Entre 10 de julho de 2013 e 30 de junho de 2018, por exemplo, o IPCA acumulado do Brasil foi de $35,75 \%$; assim sendo, se os valores de repasse tivessem sido atualizados por esse índice, se teria os valores apresentados na tabela 1, o que mostra uma elevada defasagem de correção monetária só nesse período de análise.

\section{TABELA 1}

Valores per capita atribuídos aos grupos de PAB Fixo e valores per capita corrigidos pelo IPCA (2013-2018) ${ }^{1}$

(Em R\$)

\begin{tabular}{lcc}
\hline & Valor de repasse & Valor corrigido pelo IPCA \\
\hline Grupo 4 & 23,00 & 31,22 \\
Grupo 3 & 24,00 & 32,58 \\
Grupo 2 & 26,00 & 35,29 \\
Grupo 1 & 28,00 & 38,01 \\
\hline
\end{tabular}

Fonte: Brasil (2013).

Elaboração dos autores.

Nota: ${ }^{1}$ Período compreendido entre 10 julho de 2013 e 30 junho de 2018.

Outro ponto importante é a dinâmica populacional dos municípios. Localidades que apresentam um grande crescimento populacional ao longo dos anos terão menores repasses efetivos per capita do PAB Fixo, uma vez que: o montante de recursos transferidos para o município não muda (pois é travado pela população estimada em 2012, usada para os critérios de repasse exposto na portaria), mas a população local tende a crescer, isso aumenta, inevitavelmente, a diferença entre a transferência per capita efetiva (o montante de dinheiro estabelecido na portaria e a população corrente) e o piso estabelecido (montante de dinheiro estabelecido na portaria e a população do ano referência, 2012). Neste caso, o repasse efetivo apresenta uma defasagem populacional que tende a aumentar com o passar dos anos. ${ }^{14}$

Para ver isso, basta observar as figuras H.1 e H.2 (anexo H), que mostram as transferências teóricas (estabelecidas na portaria) e as transferências efetivas (quando se leva em conta a mudança populacional) para o ano de 2014. A Portaria no $1.409 / 2013$ baseou-se na população dos municípios estimada pelo IBGE para o ano de 2012. Em 2014, naturalmente, houve uma mudança populacional nos

\footnotetext{
14. Vejamos um exemplo prático para o entendimento dessa dinâmica. São Paulo é a maior cidade do país e em 2012 possuía 11.376.685 habitantes. Em 2013, o governo federal estabeleceu o repasse do PAB Fixo em R $\$ 261.663 .755,04$, que enquadrou a cidade no piso de $\mathrm{R} \$ 23,00$ per capita, baseando-se na população estimada do ano anterior. Em 2014, que foi o primeiro ano de repasse das transferências completamente por essa nova regra, o valor total da transferência não foi alterado em termos nominais, mas a população passou a ser de 11.967 .825 habitantes (um aumento de 5,19\% em relação à 2012). Isso fez com que a transferência efetiva per capita do PAB Fixo fosse de $R \$ 21,86$, ou seja, um valor menor do que foi estabelecido pela portaria. Isso sem levar em conta o efeito da inflação.
} 
municípios em relação a 2012, fazendo com que, em boa parte deles, o repasse real per capita náo coincidisse (para menos) com o que estava previsto pelo MS. Como em geral, os municípios tendem a apresentar um crescimento populacional positivo e de aumento de demandas de saúde ao longo dos anos, isso se torna um problema sério. Assim, além do efeito de corrosão do processo inflacionário, o piso não é obedecido pelo fato de que também a regra do repasse não leva em conta a dinâmica populacional das localidades ao longo dos anos.

\section{CONSIDERAÇÕES FINAIS}

Este artigo se propôs a descrever os repasses federais para a atenção básica no âmbito do SUS, mais especificamente as transferências feitas para os municípios por meio do PAB Fixo. Teve como meta fazer uma descrição bastante detalhada dessa modalidade de transferência, apresentando um caráter preponderantemente descritivo. Para isso, primeiramente, foi presentada uma rápida descriçáo sobre a origem do SUS e o longo processo de aperfeiçoamento do seu mecanismo de financiamento nas três esferas de governo, enfatizando sua característica descentralizadora. Depois, foram destrinchados alguns aspectos de como se dá a transferência dos recursos do governo central para os municípios, também foram apresentadas as açóes e os serviços de atenção básica ofertados nessa esfera governamental.

O estudo também expôs questôes sobre a origem institucional do SUS, a lenta evolução do seu mecanismo de financiamento e, por fim, as características da sustentação financeira federal da atenção básica municipal pelo PAB Fixo. Neste último ponto, vimos como o PAB Fixo representou uma ruptura na forma de financiamento, antes baseada apenas na capacidade local de produçáo em serviços de saúde, em uma tentativa de diminuir as desigualdades de acesso a esse bem entre municípios ricos e pobres. Mostrou-se, adicionalmente, as regras da definição do valor financiado para cada município, as recomendaçóes para prestaçôes de contas do uso desse dinheiro por parte dos gestores locais, bem como as possibilidades e restriçóes do uso desse dinheiro no pagamento de açôes em saúde.

Além disso, os dados estatísticos mostrados neste trabalho evidenciaram que, embora os maiores repasses per capita tendam a ser direcionados para os municípios menos populosos, a dinâmica populacional é um importante fator que diminui a tentativa de equalizaçáo na capacidade de financiamento, uma vez que o repasse per capita efetivo tende a se tornar cada vez menor à medida que a população municipal cresce ao longo dos anos. Isso pode resultar em uma dificuldade dos municípios em realizarem a provisão adequada de serviços de saúde no nível primário de atenção.

Por fim, o trabalho evidencia a falta de atualização do valor monetário dessa transferência intergovernamental. Foi exposto que o valor per capita e/ou uma atualização dos critérios de repasse não têm sido feitas desde 2013. A falta de uma 
regra para o reajuste periódico do piso ou de como tratar as rápidas mudanças populacionais nas localidades (que alteram os repasses per capita) é um problema a serem enfrentados pelo MS. Os dois problemas podem ser resolvidos por meio da criação de regras automáticas de repasse. No caso da dinâmica populacional, a atualização pela estimativa anual que o IBGE faz para os municípios. A outra é a atualização monetária (pelo IPCA) das transferências. Uma vez não feitas essas mudanças, o PAB Fixo não cumprirá a sua função primordial que é a de garantir um mínimo de financiamento per capita na atenção básica dos municípios do país.

\section{REFERÊNCIAS}

ANDRETT, M.; ROSA, F. Eficiência dos gastos públicos em saúde no Brasil: estudo sobre o desempenho de estados brasileiros. In: CONGRESSO BRASILEIRO DE CUSTOS-ABC. 22., nov. 2015, Foz do Iguaçu, Paraná. Anais... Foz do Iguaçu: CBC, 2015.

ARRETCHE, M. Financiamento federal e gestão local de políticas sociais: o difícil equilíbrio entre regulação, responsabilidade e autonomia. Ciência \& Saúde Coletiva, v. 8, p. 331-345, 2003.

Federalismo e políticas sociais no Brasil: problemas de coordenação e autonomia. Sáo Paulo em Perspectiva, v. 18, n. 2, p. 17-26, 2004.

BAICKER, K.; CHANDRA, A. Medicare spending, the physician workforce, and beneficiaries' quality of care. Health Affairs, v. 23, n. 3, p. 291-291, 2004.

BARBOSA, M. G. et al. Financiamento da atenção básica à saúde no Brasil: do Piso da Atenção Básica à remuneração por desempenho. In: GOMES, L. B.; BARBOSA, M. G.; FERLA, A. A. (Orgs.). Atençáo básica: olhares a partir do Programa Nacional de Melhoria do Acesso e da Qualidade - (PMAQ-AB). 1. ed. Porto Alegre: Rede Unida, 2016.

BASTOS, F.; SANTOS, E.; TOVO, M. Capital social e Sistema Único de Saúde no Brasil. Saúde e Sociedade, v. 18, n. 2, p. 177-188, 2009.

BRASIL. Ministério da Saúde. Programa de Atençáo Básica: parte fixa. Brasília: SE/MS, 2001.

. Ministério da Saúde. Portaria no 1.409, de 10 de julho de 2013. Define o valor mínimo da parte fixa do Piso de Atenção Básica (PAB) para efeito do cálculo do montante de recursos a ser transferido do Fundo Nacional de Saúde aos fundos de saúde dos municípios e do Distrito Federal, e divulga os valores anuais e mensais da parte fixa do PAB. Diário Oficial da Uniáo, Brasília, 11 jul. 2013. Disponível em: <https://bit.ly/2TP0Xh7>. 
BROLLO, F. et al. The political resource curse. The American Economic Review, v. 103, n. 5, p. 1759-1796, 2013.

CAMINAL, H. et al. Primary health care and hospitalization in ambulatory care sensitive conditions in Catalonia. Rev. Clin. Esp., v. 201, p. 501-507, 2001.

CNM - CONFEDERAÇÃO NACIONAL DE MUNICÍPIOS. Recursos financeiros no Sistema Único de Saúde. Brasília: CNM, 2014.

DIAS, L. et al. Fatores associados ao desperdício de recursos da saúde repassados pela União aos municípios auditados pela Controladoria-Geral da União. Revista Contabilidade \& Finanças-USP, v. 24, n. 63, 2013.

MACHADO, E. N. D. M.; FORTES, F. B. C. T. P.; SOMARRIBA, M. Efeitos da introdução do $\mathrm{PAB}$ sobre a distribuiçáo de recursos e a prestaçáo de serviços: o caso de Minas Gerais. Ciência \& Saúde Coletiva, v. 9, p. 99-111, 2004.

MARQUES, R.; MENDES, A. A problemática do financiamento da saúde pública brasileira: de 1985 a 2008. Economia e Sociedade, v. 21, n. 2, p. 345-362, 2012.

MAZON, L.; MASCARENHAS, L.; DALLABRIDA, V. Eficiência dos gastos públicos em saúde: desafio para municípios de Santa Catarina. Saúde e Sociedade, v. 24, p. 23-33, 2015.

MELAMED, C.; COSTA, N. Inovaçôes no financiamento federal à atenção básica. Ciência \& Saúde Coletiva, v. 8, n. 2, 2003.

MENDES, A. Financiamento, gasto e gestáo do Sistema Único de Saúde: a gestáo descentralizada semiplena e plena do sistema municipal no estado de São Paulo (1995-2001). Tese (Doutorado em Ciências Econômicas) - Instituto de Economia, Universidade Estadual de Campinas, Campinas, 2005.

MENDES, A.; MARQUES, R. M. O financiamento da atenção básica e da estratégia saúde da família no Sistema Único de Saúde. Saúde em Debate, v. 38, n. 103, p. 900-916, 2014.

MENEZES, A. The impact of decentralization revenue on economic growth and wellbeing. In: CONGRESS LATINS AMERICAN AND CARIBBEAN REGIONAL SCIENCE ASSOCIATION INTERNATIONAL; ENCONTRO NACIONAL DA ASSOCIAÇÃO BRASILEIRA DE ESTUDOS REGIONAIS E URBANOS, 1; 15., 2017, São Paulo, São Paulo. Anais... São Paulo: Enaber, 2017.

NEDEL, F. B. et al. Conceptual and methodological aspects in the study of hospitalizations for ambulatory care sensitive conditions. Ciência \& Saúde Coletiva, v. 16, p. 1145-1154, 2011.

PAIM, J. et al. O sistema de saúde brasileiro: história, avanços e desafios. The Lancet, 2011. 
REMOR, L. et al. Indicadores de saúde como apoio à gestão dos SUS. Inter Science Place, v. 1, n. 15, 2010.

SIMÃO, J.; ORELLANO, V. Um estudo sobre a distribuição das transferências para o setor de saúde no Brasil. Estudos Econômicos, São Paulo, v. 45, n. 1, p. 33-63, 2015.

STARFIELD, B.; SHI, L. Policy relevant determinants of health: an international perspective. Health Policy, v. 60, n. 3, p. 201-218, 2002. 
ANEXO A

\section{FONTES DE RECEITAS DO FINANCIAMENTO DA SAÚDE NO BRASIL}

1) Fontes de receitas da União

a) Orçamento fiscal: recursos provenientes dos impostos, como Imposto Sobre Produtos Industrializados (IPI), Imposto sobre Operaçóes Financeiras (IOF) e Imposto de Renda (IR);

b) Orçamento da Seguridade Social: recursos provenientes das contribuiçôes sociais, como Contribuição para o Financiamento da Seguridade Social (Cofins), Contribuição Social sobre o Lucro Líquido (CSLL) e Programa de Integração Social/Programa de Formação do Patrimônio do Servidor Público (PIS/Pasep).

3) Fontes de receitas dos estados

a) Impostos estaduais: Imposto sobre Circulação de Mercadorias e Serviços (ICMS), Imposto sobre a Propriedade de Veículos Automotores (IPVA) e Imposto sobre Transmissão Causa Mortis e Doação (ITCMD) - sobre herança e doações;

b) Transferências da União: cota-parte do Fundo de Participação dos Estados (FPE), cota-parte do IPI-Exportação, transferências da Lei Complementar (LC) no 87/1996 - Lei Kandir;

c) IR retido na fonte;

d) Outras receitas correntes: receita da dívida ativa de impostos e multas, juros de mora e correção monetária de impostos.

Desse total, devem-se subtrair as transferências constitucionais e legais que são feitas aos municípios, que são: 25\% do ICMS, 50\% do IPVA e 25\% do IPI-Exportação.

5) Fontes de receitas dos municípios

a) Impostos municipais: Imposto Sobre Serviços (ISS), Imposto Predial e Territorial Urbano (IPTU), Imposto sobre a Transmissão de Bens Imóveis (ITBI);

b) Transferências da União: cota-parte do Fundo de Participação dos Municípios (FPM), cota-parte do Imposto sobre a Propriedade Territorial Rural (ITR) e transferências da LC no 87/1996 - Lei Kandir; 
O SUS e a Atenção Primária no Brasil: uma análise sobre o seu financiamento pelo piso

c) IR retido na fonte;

d) Transferências do estado: cota-parte do ICMS, cota-parte do IPVA e cota-parte do IPI-Exportação;

e) Outras receitas correntes: receita da dívida ativa de impostos, multas, juros e correção monetária de impostos.

\section{REFERÊNCIA}

BRASIL. Ministério da Saúde. Entendendo o SUS. Brasília: MS, 21 jun. 2006. Disponível em: <https://bit.ly/2I36EFy>. 
ANEXO B

\section{QUAIS AS AÇÕES DE SAÚDE QUE PODERIAM SER FINANCIADAS COM OS RE- CURSOS DO PISO DE ATENÇÃO BÁSICA FIXO (PAB FIXO), ATÉ 2017}

O PAB Fixo consiste em um valor mínimo de recursos financeiros destinados ao custeio de procedimentos e açôes de assistência básica, tipicamente municipal. Esses recursos financiam:

- consultas médicas em especialidades básicas;

- atendimento odontológico básico;

- atendimentos básicos por outros profissionais de nível superior e nível médio;

- visita e atendimento ambulatorial e domiciliar do Programa Saúde da Família (PSF);

- vacinação;

- atividades educativas a grupos da comunidade;

- assistência pré-natal e ao parto domiciliar;

- atividades de planejamento familiar;

- pequenas cirurgias; e

- pronto atendimento em unidade básica de saúde.

Exemplificando as ações e atividades da atenção básica.

1) Executadas por profissionais de nível médio:

a) aplicação de vacinas; administração de medicamentos, inclusive tuberculose; coleta de linfa para pesquisa de hanseníase; coleta de material para exame laboratorial; inalação e nebulização; retirada de pontos por pacientes; terapia de reidratação oral; pesquisa de plasmódios-gota espessa (diagnóstico malária).

2) Atividades em grupo:

a) atividade educativa em grupo da comunidade por profissional de nível médio; atividades executadas por agente comunitário de saúde (ACS); visita domiciliar por profissional de nível médio. 
3) Executadas por profissionais de nível superior:

a) consulta/atendimento de enfermeiro; terapias em grupo executadas por profissional de nível superior; terapias individuais; atividade educativa em grupo da comunidade por profissional de nível superior; atividade educativa em grupo da comunidade por Programa de Agentes Comunitários de Saúde (PACS)/PSF; consulta/atendimento na unidade do PACS/PSF; visita domiciliar/consulta/atendimento pelo PACS/PSF.

4) Consulta médica:

a) do PSF; de pré-natal domiciliar; para hanseníase; em clínica médica; em ginecologia; em obstetrícia; em pediatria; consulta/atendimento urgência (com remoção).

5) Procedimentos médicos cirúrgicos:

a) excisão/sutura simples de pequenas lesóes de pele/mucosa; frenectomia; retirada de corpo estranho da cavidade auditiva/nasal; incisão e drenagem de abscesso.

6) Básicas em odontologia:

a) procedimentos coletivos;

b) consulta odontológica - primeira consulta;

c) odontologia preventiva: aplicação de cariostático por dente; escariação por dente; controle da placa bacteriana; aplicação de selante por dente;

d) dentística básica: capeamento pulpar direto em dente permanente; pulpotomia de dente decíduo ou permanente; restauração compósito de duas ou mais faces; restauração com amálgama de uma face; restauração com silicato duas ou mais faces; restauração a pino; restauração fotopolimerizável uma face; e

e) odontologia cirúrgica básica: exodontia de dente decíduo; remoção de resto radicular; exodontia de dente permanente; tratamento de alveolite; ulotomia; tratamento de hemorragia; tratamento conservador osteomielite.

7) Básicos em vigilância sanitária:

a) coleta de amostra para análise, por fiscal em vigilância sanitária;

b) atividade educativa em grupo da comunidade pela vigilância sanitária; 
c) inspeção sanitária em: piscina uso público e restrito; terreno baldio; canteiro de obra; hotéis, motéis e congêneres; cemitério/necrotério e crematório; dispensário de medicamentos; e

d) inspeção zoossanitária.

\section{REFERÊNCIA}

CNM - CONFEDERAÇÃO NACIONAL DE MUNICÍPIOS. Recursos financeiros no Sistema Único de Saúde. Brasília: CNM, 2014. p. 12-14. Disponível em: <https://bit.ly/3jYeJs8>. 
ANEXO C

\section{APLICAÇÃO DOS RECURSOS FINANCEIROS DO PAB FIXO (VIGENTE ATÉ 28 DE DEZEMBRO 2017)}

Portaria Ministério da Saúde (MS) no 3.925, de 13 de novembro de 1998.

Os recursos financeiros do Piso de Atenção Básica (PAB) poderão ser utilizados em todas as despesas de custeio e capital relacionadas entre as responsabilidades definidas para a gestáo da atenção básica e coerentes com as diretrizes do Plano Municipal de Saúde, que é a base das atividades e programaçóes desse nível de direção do Sistema Único de Saúde (SUS), sendo vedada a transferência de recursos para o financiamento de ações nele não previstas e de acordo com as seguintes orientaçóes.

1) Todas as despesas de custeio da atenção básica podem ser realizadas com recursos do $\mathrm{PAB}$, excluindo:

a) pagamento de servidores inativos;

b) pagamento de gratificação de funçâo de cargos comissionados, exceto aqueles diretamente ligados às unidades de atenção básica;

c) pagamento de assessorias/consultorias prestadas por servidor público, quando pertencente ao quadro permanente dos municípios; e

d) transferência de recursos na forma de contribuições, auxílios ou subvenções a instituiçôes privadas, inclusive as filantrópicas.

5) Todas as despesas de capital relacionadas à rede básica podem ser realizadas com recursos do $\mathrm{PAB}$, excluindo:

a) a aquisiçấo e reforma de imóveis não destinados à prestação direta de serviços de saúde à população; e

b) a aquisição de equipamentos e materiais permanentes, incluindo veículos de qualquer natureza, não destinados à realização das açôes de atenção básica.

3) As despesas decorrentes de açôes de saúde de média e alta complexidade e de assistência hospitalar não devem ser realizadas com recursos do PAB.

4) As açôes de saneamento, que venham ser executadas supletivamente pelo SUS, serão financiadas por recursos tarifários específicos e outros, da União, estados, Distrito Federal e municípios, conforme o parágrafo 3o, do art. 31, da Lei no 8.080/1990. 
5) Os recursos do $\mathrm{PAB}$ não devem substituir as fontes de recursos próprios do orçamento do município.

\section{REFERÊNCIA}

BRASIL. Ministério da Saúde. Portaria no 3.925, de 13 de novembro de 1998. Diário Oficial da Uniáo, Brasília, 14 nov. 1998. Disponível em: <https://bit. ly/3jQqvVC>. 
ANEXO D

\section{PRESTAÇÃO DE CONTAS DOS RECURSOS FINANCEIROS DO PISO DE ATENÇÃO BÁSICA FIXO (PAB FIXO)}

Portaria Ministério da Saúde (MS) no 3.925, de 13 de novembro de 1998.

De acordo com o art. 6o, do Decreto no $1.651 / 1995$, a comprovação da aplicação dos recursos transferidos do Fundo Nacional de Saúde (FNS) para os fundos estaduais e municipais de saúde, na forma do Decreto no 1.232/1994, que trata das transferências fundo a fundo, deve ser apresentada ao MS e ao estado, por meio de relatório de gestáo, aprovado pelo respectivo Conselho de Saúde.

Da mesma forma, a prestação de contas dos valores recebidos e aplicados no período deve ser aprovada no Conselho Municipal de Saúde e encaminhada ao Tribunal de Contas do estado ou do município, e, se for o caso, à Câmara Municipal.

A demonstração da movimentação dos recursos de cada conta deverá ser efetuada mediante a apresentação de extratos bancários e de sua respectiva conciliação bancária, na prestaçáo de contas ou quando solicitada pelos órgáos de controle.

É importante salientar que o art. 6o, da Portaria GM/MS noำ 1.882, de 18 de dezembro de 1997, estabelece que a transferência dos recursos do PAB será suspensa caso os municípios, por dois meses consecutivos, deixem de fornecer à Secretaria de Estado da Saúde, para que estas enviem ao MS, as informaçóes dos bancos de dados nacionais, a seguir:

- Sistema de Informação sobre Mortalidade (SIM);

- Sistema de Informações sobre Nascidos Vivos (Sinasc);

- Sistema de Vigilância Alimentar e Nutricional (Sisvan);

- Sistema de Informações sobre Agravos de Notificação (Sinan);

- Outros que venham a ser implantados.

O mesmo se aplica à falta de alimentação dos dados relativos ao Sistema de Informação Ambulatorial do Sistema Único de Saúde (SIA/SUS).

A Portaria MS no 157, de 19 de fevereiro de 1998, em seu art. 12, estabelece que a transferência dos recursos relativos aos incentivos do Programa de Agentes Comunitários de Saúde (PACS), do Programa Saúde da Família (PSF), será suspensa caso os municípios, por um período de dois meses consecutivos ou três meses alternados, deixem de alimentar o Sistema de Informação da Atenção Básica (Siab). Os municípios que venham a implantar esses programas terão três meses, após a sua qualificação, para cumprir essa exigência. 


\section{REFERÊNCIA}

BRASIL. Ministério da Saúde. Portaria no 3.925, de 13 de novembro de 1998. Diário Oficial da Uniáo, Brasília, 14 nov. 1998. Disponível em: <https://bit. ly/3jQqvVC>. 


\section{ANEXO E}

\section{PORTARIA DO PISO DE ATENÇÃO BÁSICA FIXO (PAB FIXO) QUE ATUALMENTE REGULAMENTA AS TRANSFERÊNCIAS DO FINANCIAMENTO}

Portaria Ministério da Saúde (MS) no 1.409, de 10 de julho de 2013.

Para a definição do valor mínimo do PAB Fixo, o critério adotado foi a distribuição dos municípios em quatro faixas, de acordo com pontuação que varia de 0 a 10, com base em indicadores selecionados segundo critérios determinados pelo Departamento de Atenção Básica (DAB): produto interno bruto (PIB) per capita; percentual da população com plano de saúde; percentual da população com bolsa família; percentual da populaçâo em extrema pobreza e densidade demográfica.

O PIB per capita refere-se ao ano de 2010 e é disponibilizado pelo Instituto Brasileiro de Geografia e Estatística (IBGE). Devido à enorme disparidade entre o menor e o maior valor, utilizou-se uma técnica de normalização para atribuir uma pontuação de 0 a 5 para a metade dos municípios com os menores valores do PIB per capita. A outra metade recebeu pontuação distribuída de 5 a 10 de acordo com o valor.

A densidade demográfica também é disponibilizada pelo IBGE. Assim como no caso do PIB per capita, este indicador apresenta grande disparidade entre o menor e o maior valor. Foi necessário utilizar a mesma técnica de normalizaçáo para atribuir esta pontuação.

Os dados referentes à cobertura da população de cada município com planos de saúde são do ano de 2012, e foram disponibilizados pela Agência Nacional de Saúde (ANS). Cada município obteve uma pontuaçáo de 0 a 10, de acordo com o percentual de pessoas com plano de assistência médica.

O percentual da população em extrema pobreza foi disponibilizado pelo IBGE, com base no universo preliminar do Censo Demográfico 2010. Cada município obteve uma pontuação de 0 a 10, de acordo com o percentual de pessoas que não estâo nesta condição.

O percentual da população assistida pelo Programa Bolsa Família (PBF) foi consultado no endereço eletrônico do Ministério do Desenvolvimento Social e Combate à Fome (MDS), referente ao ano de 2010. Cada município obteve uma pontuação de 0 a 10, de acordo com o percentual de pessoas que não estấo nesta condiçấo.

Para alcançar a pontuaçáo final foi utilizada, para cada município, a menor pontuação entre a população com o PBF ou a população em extrema pobreza. 
Foram atribuídos os seguintes pesos para as variáveis:

- $\quad$ PIB per capita (peso 2);

- percentual da população com o PBF ou percentual da população em extrema pobreza (peso 1);

- percentual da população com plano de saúde (peso 0,5); e

- densidade demográfica (peso 1).

Com base na pontuação final, os municípios foram distribuídos em quatro grupos:

- grupo I: municípios com pontuação menor que 5,3 e população de até 50 mil habitantes;

- grupo II: municípios com pontuação entre 5,3 e 5,8 e população de até 100 mil habitantes; e municípios com pontuação menor que 5,3 e população entre 50 e 100 mil habitantes;

- grupo III: municípios com pontuação entre 5,8 e 6,1 e população de até 500 mil habitantes; e municípios com pontuação menor que 5,8 e população entre 100 e 500 mil habitantes; e

- grupo IV: municípios não contemplados nos itens anteriores.

Depois da definição dos municípios e cada grupo, atribuiu-se o valor do piso:

- o valor mínimo para os municípios integrantes do grupo I passa para $\mathrm{R} \$$ 28,00 por habitante ao ano;

- o valor mínimo para os municípios do grupo II passa para $\mathrm{R} \$ 26,00$ por habitante ao ano;

- o valor mínimo para os municípios do grupo III passa para $\mathrm{R} \$ 24,00$ por habitante ao ano; e

- o valor mínimo para os municípios integrantes do grupo IV passa para $\mathrm{R} \$ 23,00$ por habitante ao ano.

\section{REFERÊNCIA}

BRASIL. Ministério da Saúde. Portaria no 1.409 , de 10 de julho de 2013. Define o valor mínimo da parte fixa do Piso de Atenção Básica (PAB) para efeito do cálculo do montante de recursos a ser transferido do Fundo Nacional de Saúde aos fundos de saúde dos municípios e do Distrito Federal, e divulga os valores anuais e mensais da parte fixa do PAB. Diário Oficial da Uniáo, Brasília, 11 jul. 2013. Disponível em: <https://bit.ly/2TP0Xh7>. 


\section{ANEXO F}

\section{FIGURA F.1}

Distribuição espacial das transferências do Piso de Atenção Básica Fixo (PAB Fixo), estabelecidas na Portaria no 1.409/2013

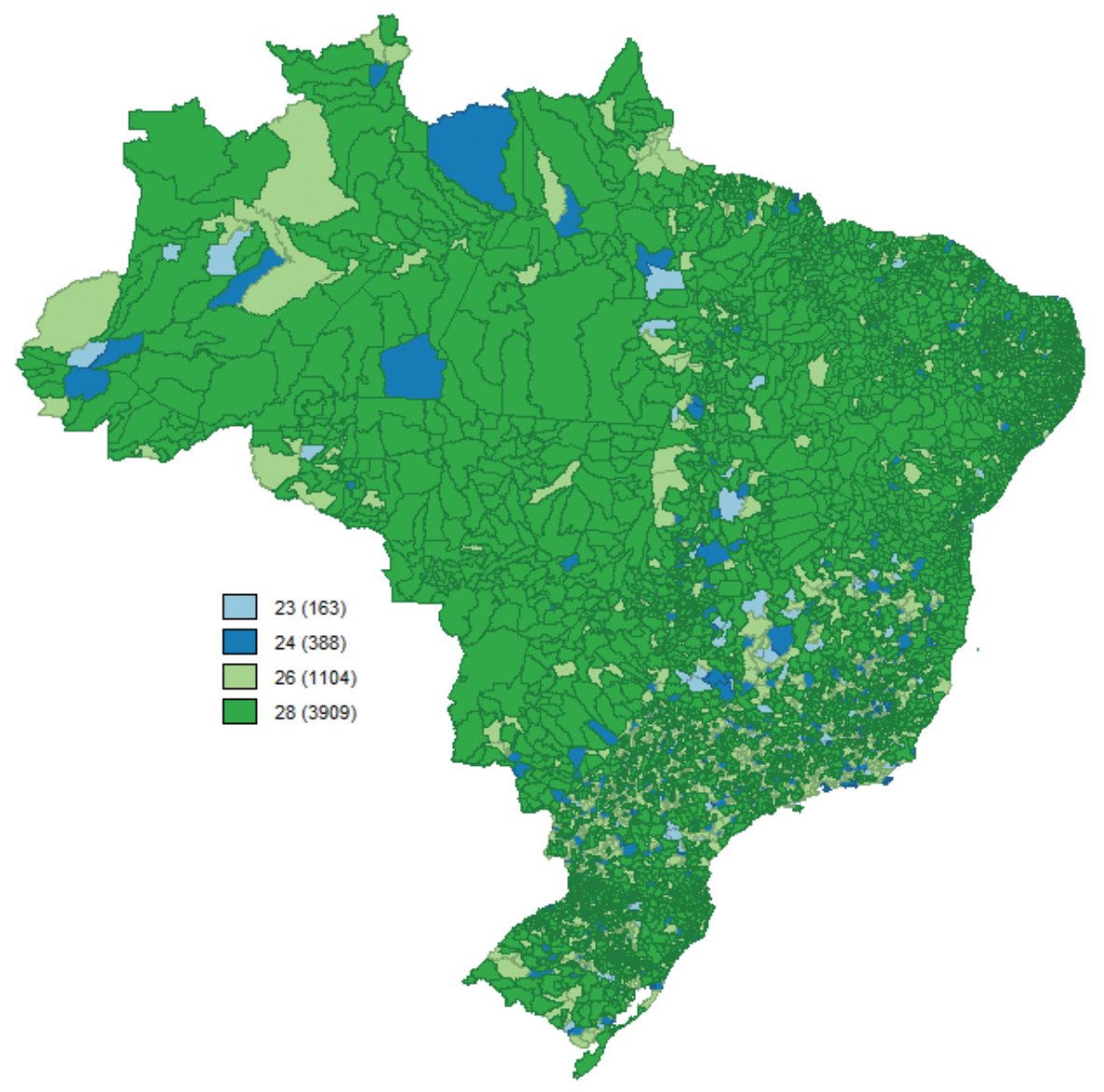

Fonte: Brasil (2013).

\section{REFERÊNCIA}

BRASIL. Ministério da Saúde. Portaria no 1.409, de 10 de julho de 2013. Define o valor mínimo da parte fixa do Piso de Atenção Básica (PAB) para efeito do cálculo do montante de recursos a ser transferido do Fundo Nacional de Saúde aos fundos de saúde dos municípios e do Distrito Federal, e divulga os valores anuais e mensais da parte fixa do PAB. Diário Oficial da Uniáo, Brasília, 11 jul. 2013. Disponível em: <https://bit.ly/2TP0Xh7>. 


\section{ANEXO G}

GRÁFICO G.1

Transferências efetivas do Piso de Atenção Básica Fixo (PAB Fixo) dos grupos I e II pelo critério populacional ${ }^{1}$
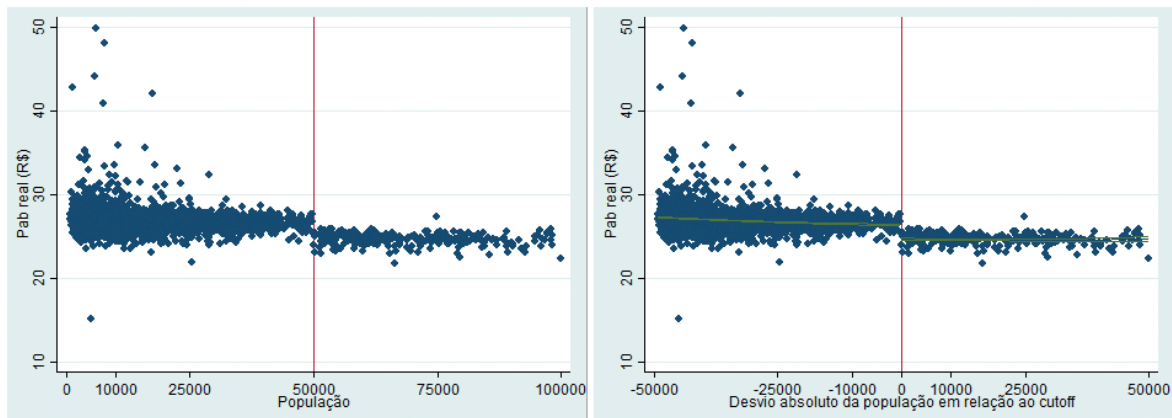

Fonte: Fundo Nacional de Saúde (2014-2016). Disponivel em: <https://bit.ly/330kUGx>. Acesso em: 10 jul. 2017.

Nota: ${ }^{1}$ A figura da esquerda mostra o scatterplot do PAB efetivo versus o tamanho populacional do município. Na figura da direita, tem-se a estimação da média (ajustada com um polinômio de segunda ordem) e do desvio-padrão a um intervalo de confiança de $95 \%$.

Obs.: Gráfico cujos leiaute e textos não puderam ser padronizados e revisados em virtude das condições técnicas dos originais (nota do Editorial).

\section{GRÁFICO G.2}

Transferências efetivas do PAB Fixo dos grupos II e III pelo critério populacional ${ }^{1}$
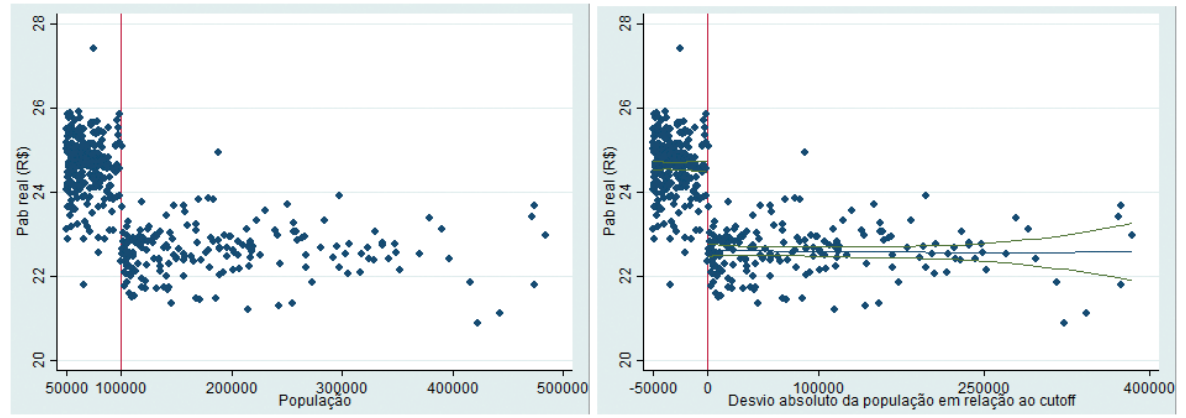

Fonte: Fundo Nacional de Saúde (2014-2016). Disponível em: <https://bit.ly/330kUGx>. Acesso em: 10 jul. 2017.

Nota: ${ }^{1}$ A figura da esquerda mostra o scatterplot do PAB efetivo versus o tamanho populacional do município. Na figura da direita, tem-se a estimação da média (ajustada com um polinômio de segunda ordem) e do desvio-padrão a um intervalo de confiança de 95\%.

Obs.: Gráfico cujos leiaute e textos não puderam ser padronizados e revisados em virtude das condições técnicas dos originais (nota do Editorial). 
GRÁFICO G.3

Transferências efetivas do PAB Fixo dos grupos III e IV pelo critério populacional ${ }^{1}$

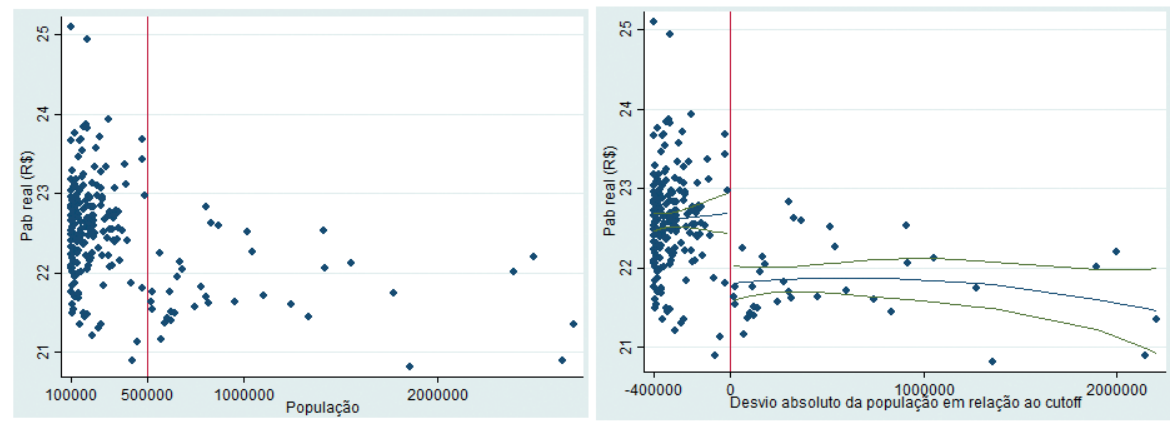

Fonte: Fundo Nacional de Saúde (2014-2016). Disponível em: <https://bit.ly/330kUGx>. Acesso em: 10 jul. 2017.

Nota: ${ }^{1}$ A figura da esquerda mostra o scatterplot do PAB efetivo versus o tamanho populacional do município. Na figura da direita, tem-se a estimação da média (ajustada com um polinômio de segunda ordem) e do desvio-padrão a um intervalo de confiança de $95 \%$. 


\section{ANEXO H}

FIGURA H. 1

Distribuição espacial das transferências teóricas do Piso de Atenção Básica Fixo (PAB Fixo) - 2014

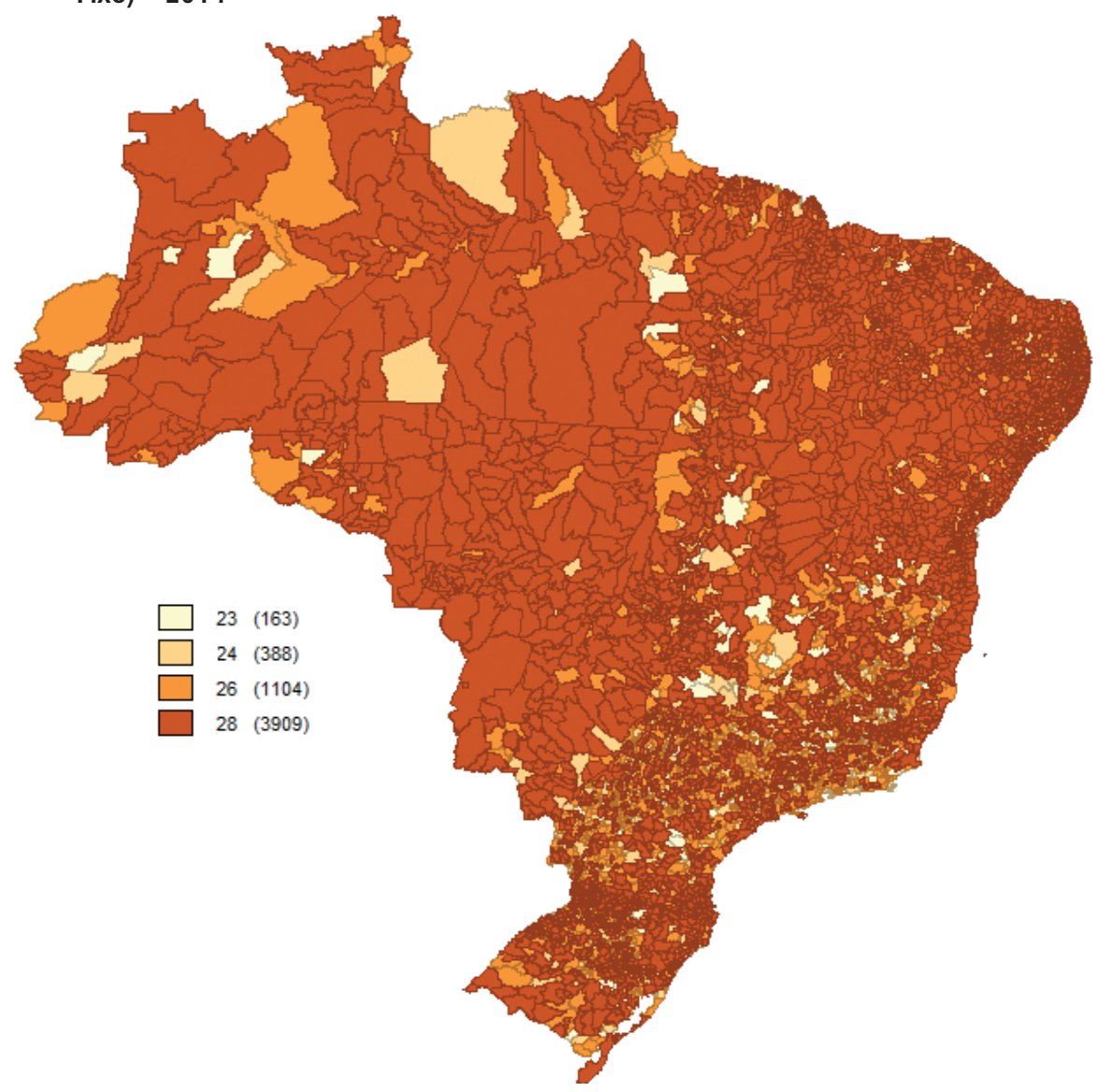

Fonte: Brasil (2013). 


\section{FIGURA H.2}

Distribuição espacial das transferências efetivas do PAB Fixo - 2014

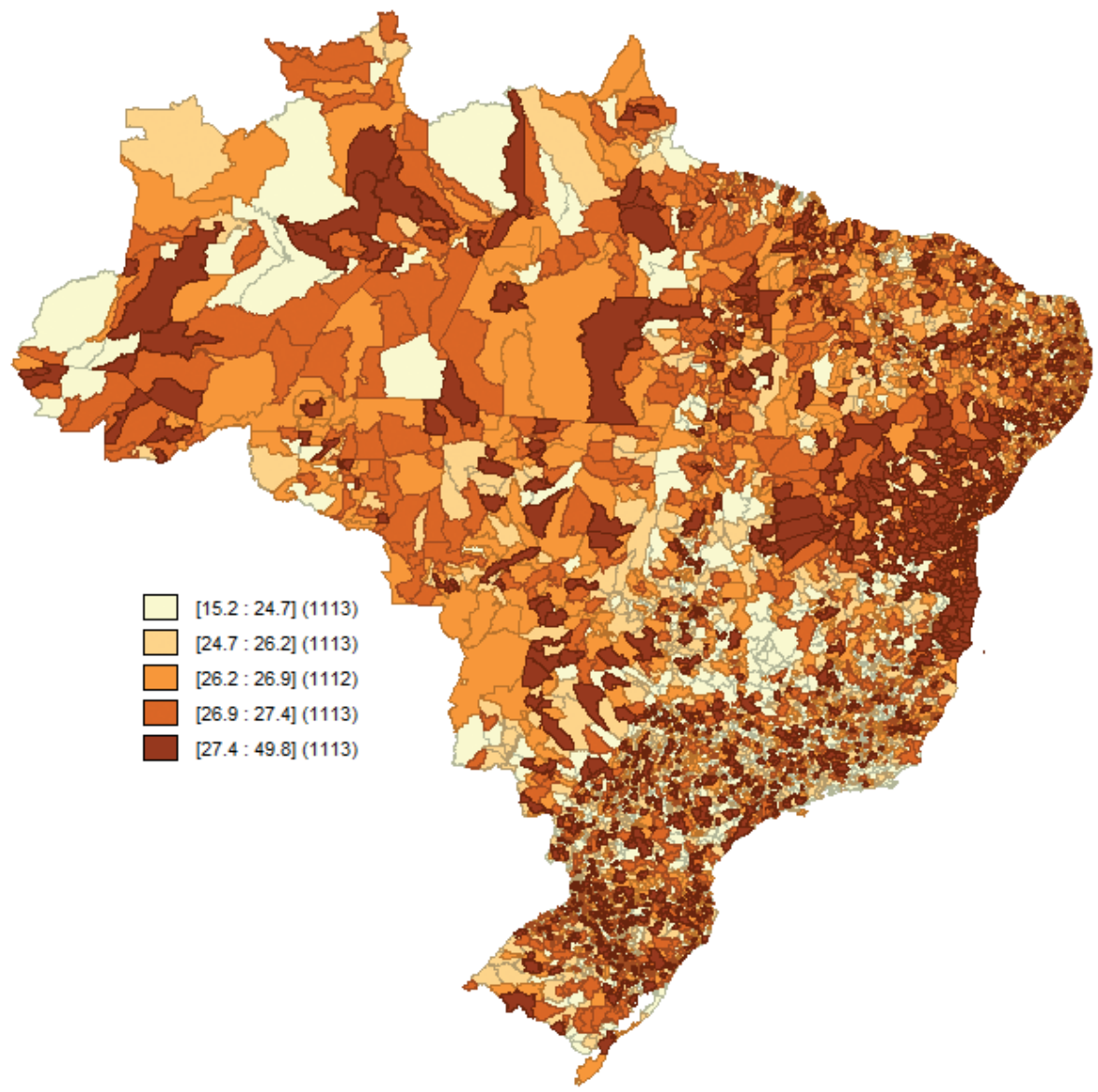

Fonte: Fundo Nacional de Saúde (2014-2016). Disponível em: <https://bit.ly/330kUGx>. Acesso em: 1 jul. 2017. 


\section{REFERÊNCIA}

BRASIL. Ministério da Saúde. Portaria no 1.409 , de 10 de julho de 2013. Define o valor mínimo da parte fixa do Piso de Atenção Básica (PAB) para efeito do cálculo do montante de recursos a ser transferido do Fundo Nacional de Saúde aos fundos de saúde dos municípios e do Distrito Federal, e divulga os valores anuais e mensais da parte fixa do PAB. Diário Oficial da Uniáo, Brasília, 11 jul. 2013. Disponível em: <https://bit.ly/2TP0Xh7>.

Data da submissão: $2 / 7 / 2018$

Primeira decisão editorial em: 25/9/2018

Última versão recebida em: 3/12/2018

Aprovação final em: 3/12/2018 